\title{
Design of ANFIS Estimator of Permanent Magnet Brushless DC Motor Position for PV Pumping System
}

\author{
TERKI Amel \\ Genie Electric department \\ Biskra University \\ Biskra, Algeria
}

\author{
MOUSSI Ammar \\ Genie Electric department \\ Biskra University \\ Biskra, Algeria
}

\author{
TERKI Nadjiba \\ Genie electric department \\ Biskra University \\ Biskra, Algeria
}

\begin{abstract}
This paper presents a new scheme for PMBLDC (permanent magnet brushless direct current) rotor position estimation based an ANFIS (adaptive network fuzzy inference system) estimator. The operation of such motor requires accurate rotor position knowledge. However, most of rotor position sensors produce undesirable effects such as mechanical losses and have other disadvantages. In order to overcome the disadvantages, sensorless scheme seems to offer great advantages. This work present an ANFIS estimator design. Combining the adaptive capability of the neural network to gather with the reasoning ability of the fuzzy logic in ANFIS modeling results in a fast responding and flexible model. This procedure lends itself perfectly adapted for complex system such as PV pumping systems.
\end{abstract}

Keywords-Photovoltaic system; Brushless DC motor; ANFIS estimator; Speed controller

\section{INTRODUCTION}

In early1980s, DC motors are widely used for PV pumping applications either with or without intermediate converters [1]. Starting, steady state, and transient performances of solar power fed DC motors for linear and centrifugal pump load torques were analyzed and showed a perfect matching [2]. However these motors a bulky, and require frequent maintenance. Nowadays solar power fed permanent magnet brushless DC (PMBLDC) motors were being used instead [2].

PMBLDC machine is more popular due its simple structure and low cost $[1,3]$. These machines have the advantages of light weight, small size, simple mechanical construction, easy maintenance, good reliability, and high efficiency $[1,3,4,5]$. In general, the motors are equipped with mechanical position detecting devices to provide proper commutation for power devices in the bridge inverter [6]. These mechanical devices, such as Hall Effect sensor, optical or inductive sensor produce undesirable effects such as mechanical losses and also have other disadvantages like change in mechanical design and requirement of maintenance.

In order to overcome these drawback, there is a need to develop a sensorless scheme for estimating rotor position.
In recent years, many sensorless drive methods have been proposed. Of these, the most popular one in the back emf based Filter (EKF) is used [7]. This method provides excellent speed response but requires heavy online matrix computing. An offline FEM assisted position and speed observer has also been studied in the literature [8]. Zero crossing of line to line PM flux linkage is used for estimating the speed and position [9]. Flux Linkage Observer (FLO) based on the integration of back EMF, with a simple start-up method is proposed [10].

In this paper the design of an ANFIS estimator of permanent magnet brushless DC motor in PV pumping system is presented. The Adaptive Neuro Fuzzy Inference System (ANFIS), is a neural network that is functionally the same as a Takagi-Sugeno type inference model. The ANFIS is a hybrid intelligent system that takes advantages of both ANN and fuzzy logic theory in a single system, by using the ANN technique to update the Takagi-Sugeno type inference model parameters. In order to explain the concept of ANFIS structure, five distinct layers are used. The first layer in the ANFIS structure is the fuzzification layer; the second layer performs the rule base layer; the third layer performs the normalisation of membership functions (MFs); the fourth and fifth layers are the defuzzification and summation layer respectively [11].

This rest of the paper is organized as follows. In section 2, the configuration of PV pumping systems is presented, The Adaptive network fuzzy inference system estimator is described in section 3. Section 4 shows the experimental performance of Adaptive network fuzzy inference system estimator. Finally, Section 5 concludes our contribution and merits of this work.

\section{GENERAL SySTEM LAYOUT}

The full system mainly consists of the solar cell array generator, DC/DC converter with MPPT (maximum power point tracker) command, PMBLDC motor with its bridge inverter coupled to a centrifugal pump load. The motor is controlled through a hysteresis current loop and an outer speed with PI type controller as shown in fig1. 


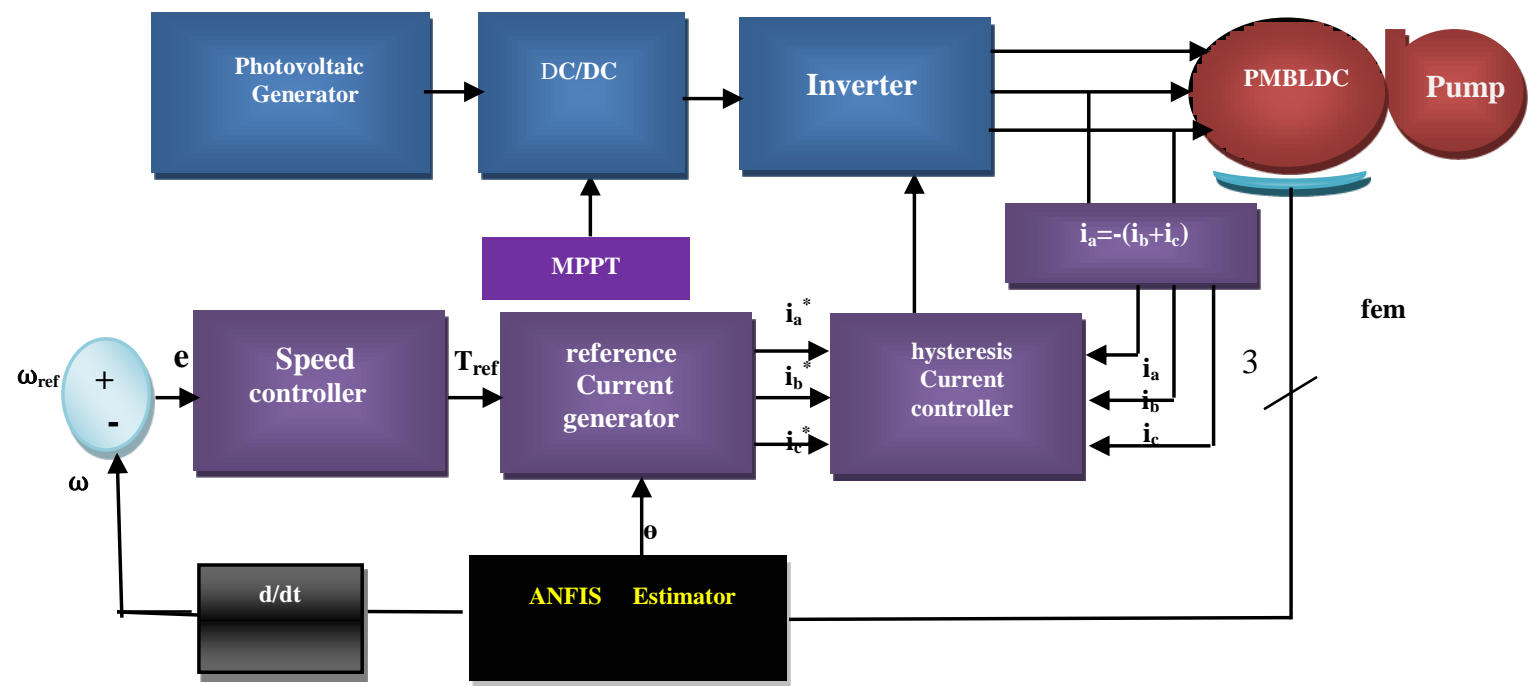

Fig. 1. Overall system configuration

\section{A. PV generator model}

The characteristic of the Photovoltaic generator can be presented by the following nonlinear equation [4]:

$$
I=I_{s c}-I_{o}\left[\exp \left(\frac{\left(V+R_{s} I\right)}{V_{t h}}\right)-1\right]-\frac{\left(V+R_{s} I\right)}{R_{s h}}
$$

Where:

$\mathrm{I}_{\mathrm{PV}}$ Array output current,

$\mathrm{R}_{\text {sh }} \mathrm{PV}$ array equivalent shunt resistance,

$\mathrm{I}_{\mathrm{sc}} \quad \mathrm{PV}$ array short circuit current,

$\mathrm{I}_{\mathrm{o}} \quad \mathrm{PV}$ array reverse saturation current,

$\mathrm{R}_{\mathrm{s}} \quad \mathrm{PV}$ array series resistance,

$\mathrm{V}_{\text {th }}$ PV array thermal voltage.

The thermal voltage $\mathrm{V}_{\text {th }}$ and $\mathrm{t}$ reverse saturation current Io are successively identified by [4]:

$$
\begin{aligned}
& V_{t h}=\frac{\left(V_{o p}+R_{s} I_{o p}-V_{o c}\right)}{\log \left(1-\frac{I_{o p}}{I_{s c}}\right)} \\
& I_{o}=\left(I_{s c}-I_{o P}\right) \exp \left(-\frac{\left(V_{o p}+R_{s} I_{o p}\right)}{V_{r h}}\right)
\end{aligned}
$$

\section{B. Permanent magnet Brush-Less DC motor model}

The simplified schematic of PMBLDC motor who has a trapezoidal electromotive force, the use of Park transform is not the best approach in modelling the machine. Instead the natural approach in used where the emf is generated with respect to rotor position [4]. The operating sequences of the machine can be subdivided into six cycles with respect to rotor position as shown in table II.

The electric of the motor can be described by [4]

$$
V_{a n}=R i_{a}+p \lambda_{a}+e_{a}
$$

$$
\begin{gathered}
V_{b n}=R i_{b}+p \lambda_{b}+e_{b} \\
V_{c n}=R i_{c}+p \lambda_{c}+e_{c}
\end{gathered}
$$

With

$$
\begin{aligned}
& V_{a n}=V_{a 0}-V_{n 0} \\
& V_{b n}=V_{b 0}-V_{n 0} \\
& V_{c n}=V_{c 0}+V_{n 0}
\end{aligned}
$$

Where R: per phase stator resistance. $i_{a, b, c}$ and $\lambda_{a, b, c}$ are respectively phase currents of phases $\mathrm{a}, \mathrm{b}$ and $\mathrm{c}$ and total flux linkage of a,b and c. p: Laplace operator.

The flux expressions are given by the following expressions:

$$
\begin{gathered}
\lambda_{a}=L_{S} i_{a}-M\left(i_{b}+i_{c}\right) \\
\lambda_{b}=L_{S} i_{b}-M\left(i_{a}+i_{c}\right) \\
\lambda_{c}=L_{S} i_{c}-M\left(i_{a}+i_{b}\right)
\end{gathered}
$$

Where Ls: the self-inductance and M: the mutual inductance.

And

$$
i_{a}+i_{b}+i_{c}=0
$$

Therefore by substituting Eq.13 in Eqs 10, 11 and 12:

$$
\begin{aligned}
\lambda_{\mathrm{a}} & =\mathrm{i}_{\mathrm{a}}\left(\mathrm{L}_{\mathrm{S}}+\mathrm{M}\right) \\
\lambda_{\mathrm{b}} & =\mathrm{i}_{\mathrm{b}}\left(\mathrm{L}_{\mathrm{S}}+\mathrm{M}\right) \\
\lambda_{\mathrm{c}} & =\mathrm{i}_{\mathrm{c}}\left(\mathrm{L}_{\mathrm{S}}+\mathrm{M}\right)
\end{aligned}
$$

From the electrical equations 4,5 and 6 , the following system is obtained

$$
\left[\begin{array}{l}
V_{a n} \\
V_{b n} \\
V_{c n}
\end{array}\right]=\left[\begin{array}{lll}
R & 0 & 0 \\
0 & R & 0 \\
0 & 0 & R
\end{array}\right]\left[\begin{array}{l}
i_{a} \\
i_{b} \\
i_{c}
\end{array}\right]+p\left[\begin{array}{ccc}
L_{e q} & 0 & 0 \\
0 & L_{e q} & 0 \\
0 & 0 & L_{e q}
\end{array}\right]\left[\begin{array}{l}
i_{a} \\
i_{b} \\
i_{c}
\end{array}\right]+\left[\begin{array}{l}
e_{a} \\
e_{b} \\
e_{c}
\end{array}\right]
$$

With Leq $=\mathrm{L}_{\mathrm{S}}-\mathrm{M}$

From this system, the decoupled phase equations are obtained and the explicit current equations are given by: 
$p\left[\begin{array}{l}i_{a} \\ i_{b} \\ i_{c}\end{array}\right]=\left[\begin{array}{ccc}1 / L_{e q} & 0 & 0 \\ 0 & 1 / L_{e q} & 0 \\ 0 & 0 & 1 / L_{e q}\end{array}\right]\left[\left[\begin{array}{l}V_{a n} \\ V_{b n} \\ V_{c n}\end{array}\right]-\left[\begin{array}{ccc}R & 0 & 0 \\ 0 & R & 0 \\ 0 & 0 & R\end{array}\right]\left[\begin{array}{c}i_{a} \\ i_{b} \\ i_{c}\end{array}\right]-\left[\begin{array}{c}e_{a} \\ e_{b} \\ e_{c}\end{array}\right]\right]$

The mechanical part is expressed by the following equation:

With:

$$
J \frac{\mathrm{d} \Omega}{d t}+B \Omega=T_{e}-T_{r}
$$

$\mathrm{T}_{\mathrm{e}}$ : electromagnetic torque.

$\mathrm{T}_{\mathrm{r}}$ : Load torque

$\Omega:$ speed

$\mathrm{J}$ : moment of inertia

B : viscose friction coefficient

Neglecting the frictional coefficient and taking $\Omega=\frac{\omega}{P}$ where $\mathrm{P}$ is the pole pairs number, (19) can written as:

$$
\frac{\mathrm{d} \omega}{d t}=P .\left(T_{e}-T_{r}\right) / J
$$

The developed torque can be expressed by

$$
T_{e}=\left(e_{a} i_{a}+e_{b} i_{b}+e_{c} i_{c}\right) / \omega
$$

And the angular position is expressed by

$$
\frac{\mathrm{d} \theta}{d t}=\omega
$$

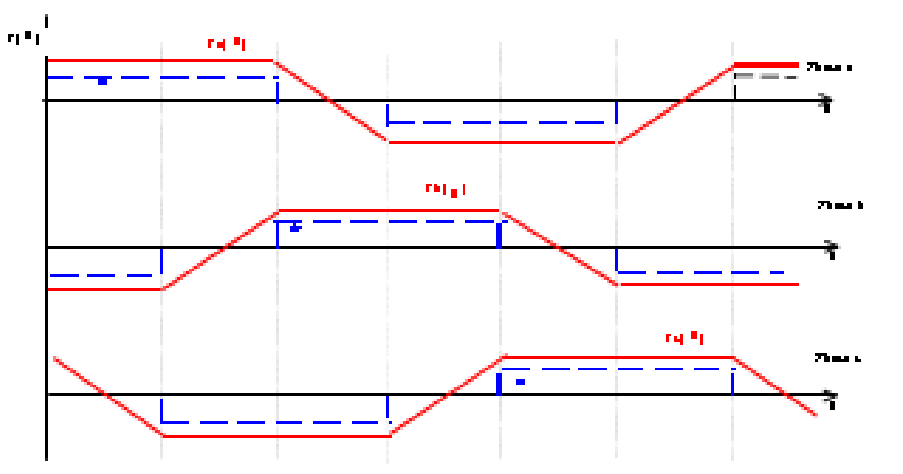

Fig. 2. Back e.m.f and current waves forms for phase $a, b$ and $c$

\section{Speed control}

PI speed controller is widely used in industry due to its ease in design and simple structure. The rotor speed $\omega(k)$ is compared with the reference speed $\omega_{\text {ref }}(k)$ and the resulting error is estimated at the $\mathrm{n}^{\text {th }}$ sampling instant as:

$$
\begin{aligned}
& e(k)=\omega_{r e f}(k)-\omega(k) \\
& \Delta e(k)=e(k)-e(k-1)
\end{aligned}
$$

The value of the torque reference is given by [4]:

$$
T_{\text {ref }}(k)=T_{\text {ref }}(k-1)+K_{P} \Delta e(k)+K_{i} e(k)
$$

Where $e(k-1)$, the speed error of previous interval is, $e(k)$ is the speed error of working interval. $k_{P}$ and $k_{i}$ are speed controller gains.

\section{Current control}

Several techniques can be used to control the phase current of the PMBLDC motor. In this paper a hysteresis current controller is used. It has the major advantage of not requiring machine parameters to be known. However the commutation frequency is not constant [4]. It depends on many factors such as the applied voltage, the back emf, hysteresis band $\Delta I$...etc.

Maximum value of commutation frequency is obtained at starting and is given by [4]:

$$
F_{\text {max }}=U / 8 L_{S} \Delta I
$$

The commutations are obtained by comparing actual currents $i_{\text {a.b.c }}$ to a rectangular reference $i^{*}{ }_{\text {a.b.c }}$ and by keeping them in hysteresis band $\Delta I$. The commutation sequences of switches are summarised in the table I. [5].

TABLE I. The CMmutation SEQuences of Switches

\begin{tabular}{|ll|l|l|l|}
\hline $\mathrm{Si}$ & $i_{a}<\left(i_{a}^{*}-\Delta I\right)$ & $\mathrm{T}_{1}$ on & $\mathrm{T}_{4}$ off & $\mathrm{V}_{\mathrm{a}}=\mathrm{U} / 2$ \\
\hline $\mathrm{Si} \quad i_{a}>\left(i_{a}^{*}+\Delta I\right)$ & $\mathrm{T}_{1}$ off & $\mathrm{T}_{4}$ on & $\mathrm{V}_{\mathrm{a}}=-\mathrm{U} / 2$ \\
\hline $\mathrm{Si} \quad i_{b}<\left(i_{b}^{*}-\Delta I\right)$ & $\mathrm{T}_{2}$ on & $\mathrm{T}_{5}$ off & $\mathrm{V}_{\mathrm{b}}=\mathrm{U} / 2$ \\
\hline $\mathrm{Si} \quad i_{b}>\left(i_{b}^{*}+\Delta I\right)$ & $\mathrm{T}_{2}$ off & $\mathrm{T}_{5}$ on & $\mathrm{V}_{\mathrm{b}}=-\mathrm{U} / 2$ \\
\hline $\mathrm{Si} \quad i_{c}<\left(i_{c}^{*}-\Delta I\right)$ & $\mathrm{T}_{3}$ on & $\mathrm{T}_{6}$ off & $\mathrm{V}_{\mathrm{c}}=\mathrm{U} / 2$ \\
\hline $\mathrm{Si} \quad i_{c}>\left(i_{c}^{*}+\Delta I\right)$ & $\mathrm{T}_{3}$ off & $\mathrm{T}_{6}$ on & $\mathrm{V}_{\mathrm{c}}=-\mathrm{U} / 2$ \\
\hline
\end{tabular}

\section{E. Pump model}

A centrifugal type is used. It can be described as an aerodynamic load which is characterised by the following load equation [4]:

$$
\mathrm{T}_{1}=\mathrm{A} \cdot \omega^{2}
$$

Where $\mathrm{A}$ is the pump constant 
TABLE II. OPERATING SEQUENCES WITH RESPECT TO ROTOR POSITION

\begin{tabular}{|c|c|c|c|c|c|c|c|c|c|}
\hline \multirow{2}{*}{$\begin{array}{c}\text { Rotor position } \\
\theta^{\circ}\end{array}$} & \multicolumn{9}{|c|}{ Phase voltages, back emf and reference current values } \\
\hline & $\mathrm{V}_{\mathrm{a} \mathrm{o}}$ & $e_{\mathrm{a}}$ & $i_{\mathrm{a}} *$ & $\mathrm{~V}_{\mathrm{bo}}$ & $e_{b}$ & $i_{b} *$ & $\mathrm{~V}_{\mathrm{co}}$ & $e_{c}$ & $i_{c}^{*}$ \\
\hline $0^{\circ}-60^{\circ}$ & $\mathrm{U} / 2$ & $\mathrm{~K}_{\tilde{z}} \omega$ & $I^{*}$ & $-\mathrm{U} / 2$ & $-K_{\approx} \omega$ & $-\mathrm{I}^{*}$ & 0 & $-6 \mathrm{~K}_{\tilde{z}} \omega \theta / \pi+\mathrm{K}_{\varepsilon} \omega$ & 0 \\
\hline $60^{\circ}-120^{\circ}$ & $\mathrm{U} / 2$ & $\mathrm{~K}_{\mathrm{e}} \mathrm{\omega}$ & $I^{*}$ & 0 & $6 \mathrm{~K}_{\ddot{z}} \omega \theta / \pi-3 \mathrm{~K}_{\ddot{\varepsilon}} \omega$ & 0 & $-\mathrm{U} / 2$ & $-\mathrm{K}_{\mathrm{z}} \omega$ & $-I^{*}$ \\
\hline $120^{\circ}-180^{\circ}$ & 0 & $-6 \mathrm{~K}_{\tilde{z}} \omega \theta / \pi+5 \mathrm{~K}_{\tilde{z}} \omega$ & 0 & $\mathrm{U} / 2$ & $\mathrm{~K} \approx \omega$ & $I^{*}$ & $-\mathrm{U} / 2$ & $-K_{\tilde{z}} \omega$ & $-I^{*}$ \\
\hline $180^{\circ}-240^{\circ}$ & $\mathrm{U} / 2$ & $-\mathrm{K}_{\mathrm{z}} \mathrm{\omega}$ & $-I^{*}$ & $\mathrm{U} / 2$ & $\mathrm{~K}_{\mathrm{e}} \mathrm{\omega}$ & $I^{*}$ & 0 & $-6 \mathrm{~K}_{\mathrm{\varepsilon}} \omega \theta / \pi+7 \mathrm{~K}_{\mathrm{\varepsilon}} \omega$ & 0 \\
\hline $240^{\circ}-300^{\circ}$ & $\mathrm{U} / 2$ & $-\mathrm{K}_{\approx} \omega$ & $-\mathrm{I}^{*}$ & 0 & $-6 \mathrm{~K}_{\varepsilon} \omega \theta / \pi+9 \mathrm{~K}_{\varepsilon} \omega$ & 0 & $\mathrm{U} / 2$ & $\mathrm{~K}_{\ddot{z}} \omega$ & $\mathrm{I}^{*}$ \\
\hline $300^{\circ}-360^{\circ}$ & 0 & $6 \mathrm{~K}_{\tilde{z}} \omega \theta / \pi-11 \mathrm{~K}_{\tilde{z}} \omega$ & 0 & $\mathrm{U} / 2$ & $-\mathrm{K}_{\tilde{z}} \omega$ & $-\mathrm{I}^{*}$ & $\mathrm{U} / 2$ & $\mathrm{~K}_{\bar{z}} \omega$ & $\mathrm{I}^{*}$ \\
\hline
\end{tabular}

\section{ANFIS ESTIMATOR}

The adaptive network fuzzy inference system play a significant role in the field of artificial intelligence. It combines the advantages of a fuzzy controller as well as quick response and adaptability nature of artificial neural network [11]. Hence using this scheme one can avoid the use of a position sensor which produces mechanical losses in the motor. Different configurations of adaptive network fuzzy inference system have been tested and the best one that gives the minimum error value is presented in fig6.

The Algorithm of the model structure was constructed as shown in Fig.3. The membership functions were obtained from the data set of the back emfs which were first normalized for loading Data. Then generate Fis, built on sugeno structure, which is obtained by creating of input membership function: number (tree inputs) \& type (triangular) and output type(linear). The choice of optimization method (hybrid) is obtained by Train Fis. If the results are satisfactory (error is minimum) after test Fis, denormalized procedure is done and go to application thereafter. The ANFIS structure consists of 5 layers of neurons, each of which having a very specific behavior.

From these, second, third and fifth layer have constant behavior, while layers 1 and 4 have varying parameters.

Layer 1: consists of five adaptive neurons in which the fuzzification is performed, that is: the grade of membership to the defined membership functions of the input is evaluated.

$$
f_{i}^{1}=\mu_{\mathrm{Ai}}(\mathrm{x})
$$

Where $\mathrm{x}$ is the input to $\mathrm{i}^{\text {th }}$ neurons and $\mathrm{Ai}$ is membership function correspond to variable $\mathrm{x}$.

The membership function $\mu_{\mathrm{Ai}}(x)$ is triangular.

Layer2: consists of 125neurons, each node output represents the firing weight of a rule gives than:

$$
\mathrm{W}_{\mathrm{k}}=\mu_{\mathrm{Ai}}(\mathrm{x}) \times \mu_{\mathrm{Bj}}(\mathrm{y})
$$

$\mathrm{k}$ : represent the number of rule, $\mathrm{i}:$ represent the number of $\mathrm{x}$ partition and $\mathrm{j}$ : number of $\mathrm{y}$ partition.

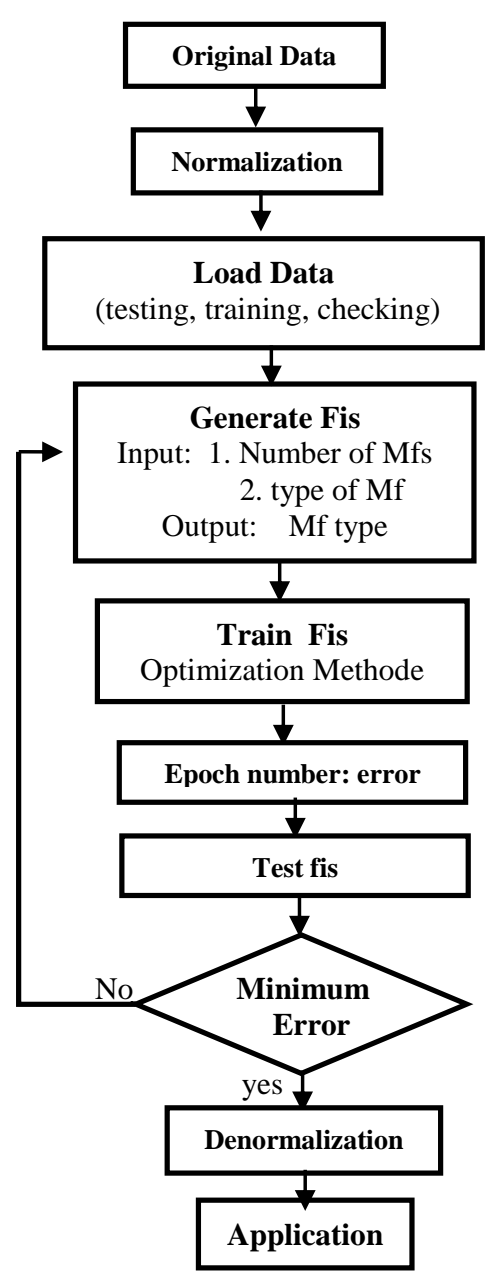

Fig. 3. Algorithm of the ANFIS model

Layer3: consists of 125 neurons, every node calculates the ratio of every rule firing weight to the sum of all rule firing weights.

$$
\overline{W_{k}}=\frac{W_{k}}{\sum W_{i}}
$$


Layer 4: consists of 125 neurons. Nodes in layer 4 are adaptive nodes in which the consequent evaluation inference is calculated, its output is defined as:

$$
f_{k}^{4}=\overline{W_{k}} \times f_{k}=\overline{W_{k}} \times\left(p_{k} x+q_{k} y+r_{k}\right)
$$

$\overline{W_{k}}$ is the output of layer 3 and $\left\{p_{i}, q_{i}, r_{i}\right\}$ is called consequent parameters.

Layer5: Finally, is single node in layer 5, where sums all the outputs from $4^{\text {th }}$ layer to compute the overall output of the network:

$$
f^{5}==\sum_{k} \overline{W_{k}} \times f_{k}^{4}
$$

\section{SimULATION RESULTS}

The entire ANFIS network architecture is represented in the Fig.6. The inputs are the three line to line back emfs of the motor namely Eab, Ebc and Eca Fig4. And the desired output is the estimated rotor position angle. For producing the above relationship with least possible error, a five layer feed forward adaptive network fuzzy inference system is used. The input layer consists of five neurons that have their inputs as the three line to line back emfs, the three hidden layers consists of 125 each and the output layer consists of a single neuron whose output is the estimated position of the rotor. The relationship between the back emf and the position of the rotor is shown in the Fig.5.

Fig.7 shows estimated rotor position by adaptative network fuzzy inference system and the error, along with real rotor position it's a case without regulation. Fig. 8 shows the estimated rotor position by adaptive network fuzzy inference system and the error, along with real rotor position the case is with PI speed control. In the comparison of the cases with control (PI regulator) and at without control, The controlled system attains the steady state in $(0.04 \mathrm{~s})$ greater than the case without regulation the system attains the steady state in $(0.023 \mathrm{~s})$, so the PI regulator slows the dynamic responses.

The performance of thThe performance of the trained adaptive network fuzzy inference system is found to have very minimal errors witch is about $1.303 \mathrm{e}^{-7}$ as seen in the Fig.7 (without control).

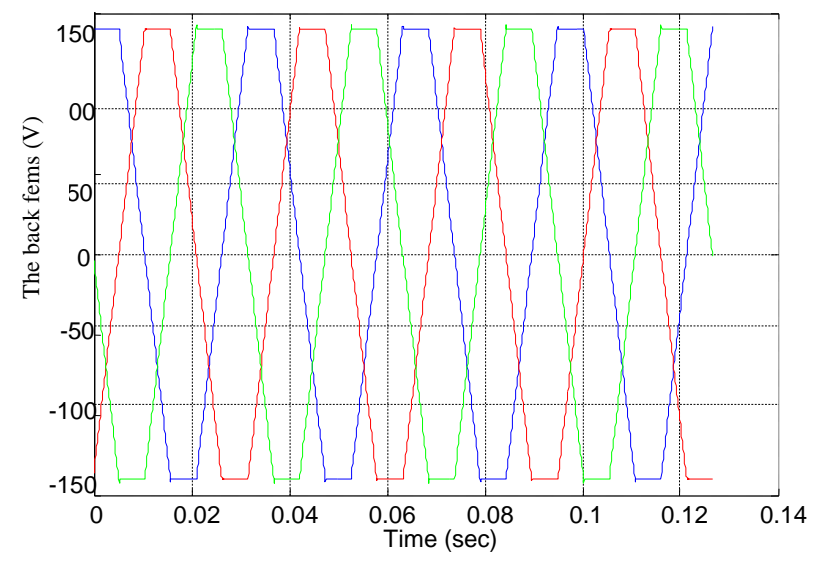

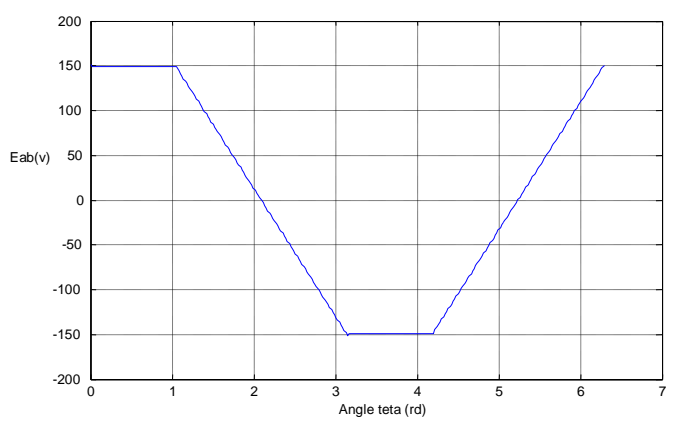

Fig. 5. The back emf Eab

For Fig.8 (with PI controller), the error is $7.8386 \mathrm{e}^{-9}$. The error of output of ANFIS and real rotor position sensor are compared through Fig.7 and Fig.8 respectively. It is clear that the error in Fig.8 is too small $\left(7.8386 \mathrm{e}^{-9}\right)$ than these in Fig.7 $\left(1.303 \mathrm{e}^{-7}\right)$. The proposed scheme works efficiently where the usage of neural network topology together with fuzzy logic in The adaptive network, ANFIS, not only includes the characteristics of both methods, but also eliminates some disadvantages of their lonely-used case.

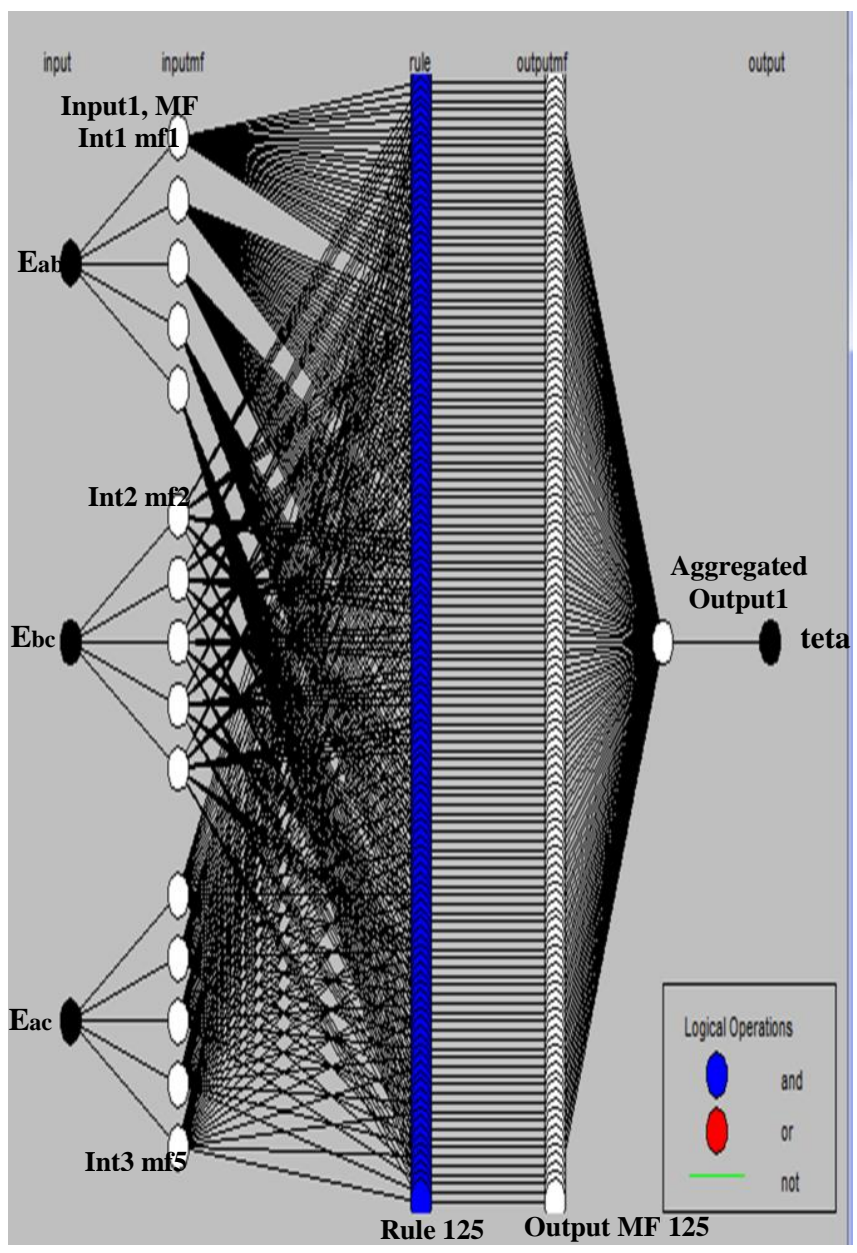

Fig. 6. Structure of ANFIS model proposed

Fig. 4. The inputs curves 

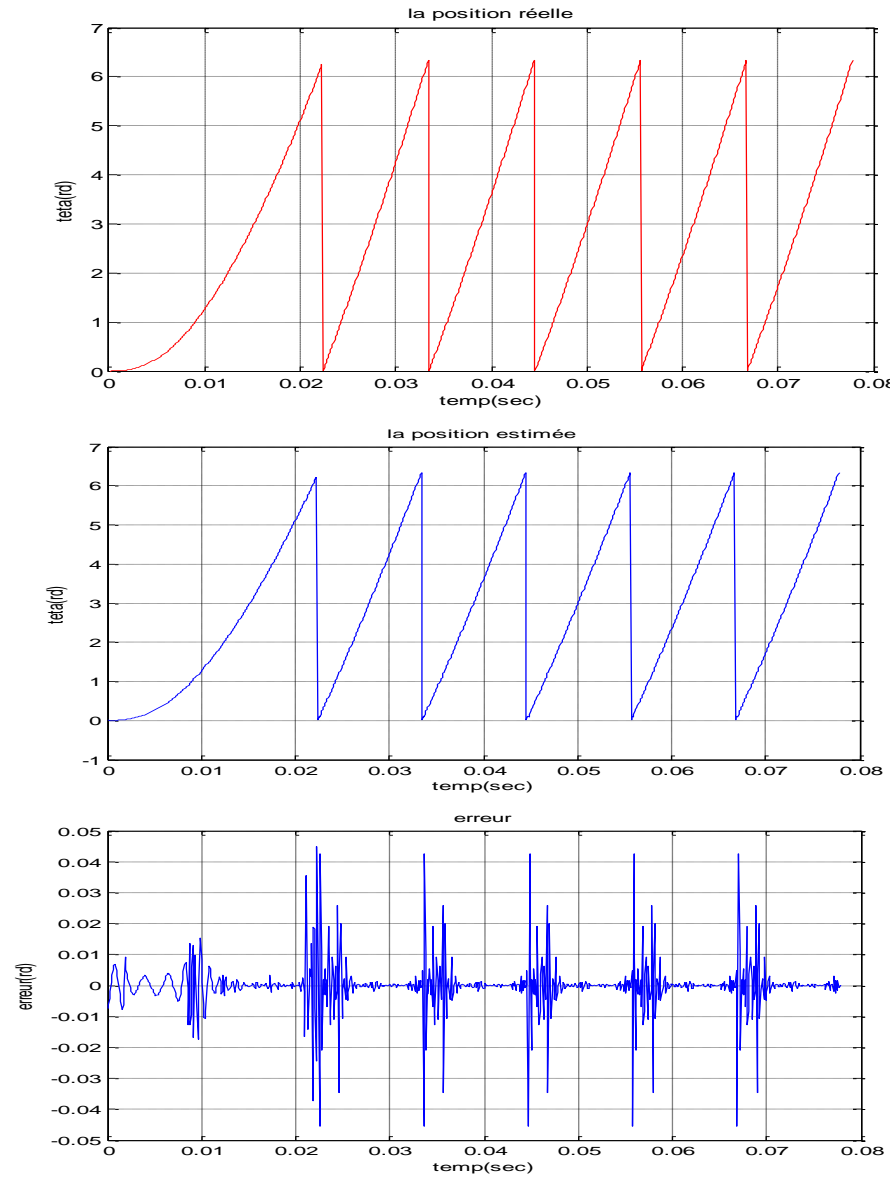

Fig. 7. Simulation Results without control
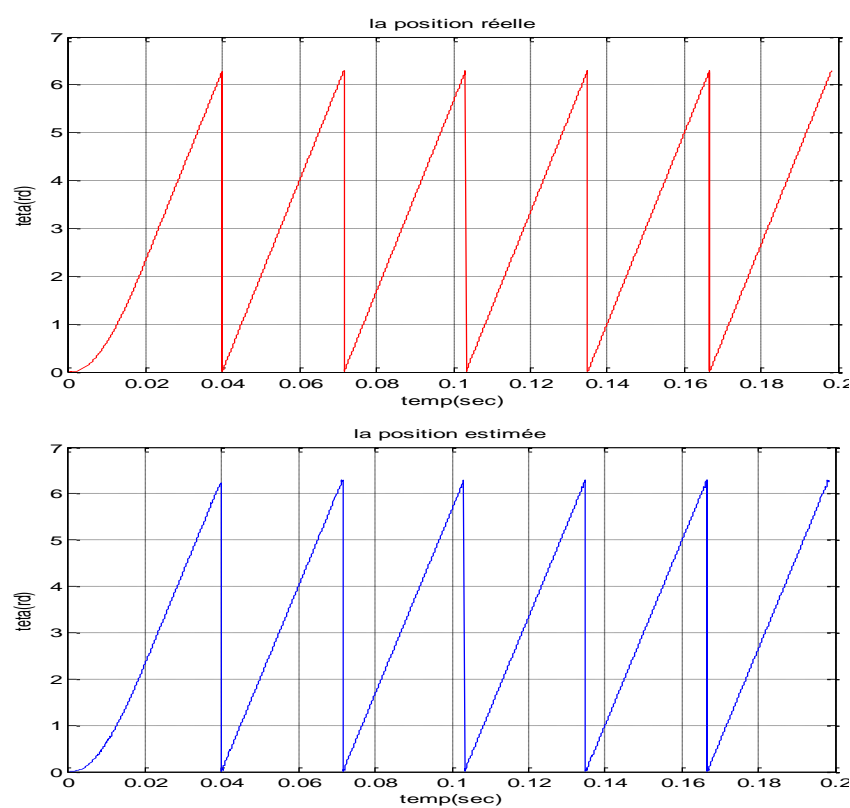

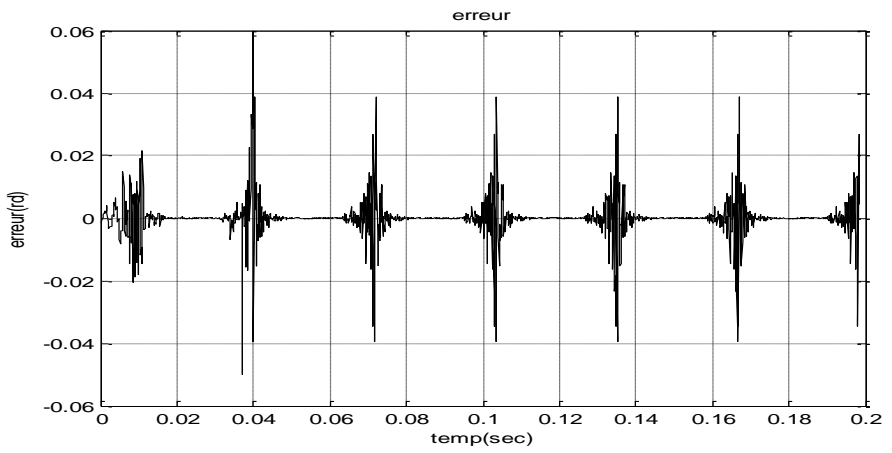

Fig. 8. Simulation Results with PI controller

\section{CONCLUSION}

The developed ANFIS models were successful in estimating rotor position of PMBLDC motor used in PV pumping system. In this paper the design of adaptive network fuzzy inference system based sensorless scheme was developed for permanent magnet brushless DC motor. The proposed scheme works efficiently for both with control (PI regulator) and at without control. It was found that the error is very minimal and this is smaller in system with regulation, than these without regulation. Also adaptive network fuzzy inference system based estimator is very flexible.

This scheme not only eliminates the position sensor, thereby cutting the cost but also transforms the drive into a highly efficient drive by eliminating losses caused by position sensors. The estimation error is found to be very minimal proving that the developed system is a very efficient and a reliable one.

\section{REFERENCES}

[1] A.Moussi, A. Saadi, A. achour, Greg Asher, Photovoltaic pumping systems technologies trends, Larhyss journal ,2003,pp.127-150.

[2] PackiamPeriasamy, N.K.Jain,I.P.Singh, A review on development of photovoltaic water pumping system, Renew.and Sustainable.Energ. Reviews, Vol. 43 ,2015, pp. 918-925.

[3] MetinDemirtas,AslanDenizKaraoglan, Optimization of PI parameters for DSP-based permanent magnet brushless motor drive using response surface methodology, Energy Conversion and Management, Vol. 56, 2012, pp. 104-111.

[4] A. Terki, A. Moussi, A. Betka, N. Terki, An improved efficiency of fuzzy logic control of PMBLDCfor PV pumping system, Appl.Math.Model, Vol. 2, 2012, pp. 934-944.

[5] A.Moussi, A.Terki, Greg Asher, Hysteresis current controller of permanent Magnet Brushless DC motor PV pumping system, ASME, 2005, pp. 523-528 [International Solar Energy conference].

[6] T. Hiyama, Neural network based estimation of maximum power generation from PV modules using environmental information, IEEE Trans. EC, Vol.12, 199, pp. 241-247.

[7] A. Ungurean, V. Coroban-Schramel and I. Boldea, Sensorless control of a BLDC PM motor based on I-f starting and Back-EMF zero-crossing detection, OPTIM '10, 2012, pp. 377-382 [Optimization of Electrical and Electronic Equipment Conference,OPTIM '10.IEEE $12^{\text {th }}$ International]. 
[8] AlinStirban, Ion Boldea, and Gheorghe-DanielAndreescu, MotionSensorless Control of BLDC-PM Motor With Offline FEM-InformationAssisted Position and Speed Observer, IEEE Trans. Ind. Appl, Vol. 48, 2012, pp. 1950-1958.

[9] LiviuIoanIepure, Ion Boldea and FredeBlaabjerg, Hybrid I-f starting and observer-based sensorless control of single phase BLDC-PM Motor drives, IEEE Trans. Ind. Electron, Vol.59, 2012,pp. 3436 - 3444.
[10] SreepriyaR\&RagamRajagopal, Sensorless Control of Three Phase BLDC Motor Drive with Improved Flux observer, ICCC, 2013, pp.292297 [IEEE International Conference on Control Communication and Computing].

[11] Ali M. Abdulshahed, AndrewP. Longstaff, Simon Fletcher, Alan Myers, Thermal error modelling of machine tools based on ANFIS withfuzzy cmeans clustering using a thermal imaging camera, Appl. Math. Model, Vol. 39, 2015, pp. 1837-1852.

APPENDIX

The PV generator, motor and pump used in this study have the following parameters: PV generator Modules AEG-40.

(Temperature $\mathrm{T}=25^{\circ} \mathrm{Cand}$ solar insolation $\mathrm{E}=1000 \mathrm{~W} / \mathrm{m}^{2}$.)

Open circuit voltage $22.40 \mathrm{~V}$

Short circuit current $2.410 \mathrm{~A}$

Series resistance $\quad 0.450 \Omega$

Current temperature coefficient $\quad 0.06 \% / \mathrm{C}$

Voltage temperature coefficient $\quad 0.40 \% / \mathrm{C}$

Centrifugal pump

Rated speed

Rated power

Flowrate

Head

Efficiency

Brushless DC motor

Rated power

Rated speed

Rated voltage

$3000 \mathrm{rev} / \mathrm{min}$

$521 \mathrm{~W}$

$2.597 \mathrm{l} / \mathrm{s}$

$14.11 \mathrm{~m}$

$69 \%$

Rated current

$690 \mathrm{~W}$

$3000 \mathrm{rev} / \mathrm{min}$

200-220V

Per phase resistance

$4.8 \mathrm{~A}$

Per phase inductance

$1 \Omega$

Poles number

$5 \mathrm{mH}$

E.m.f constant

6

0.47 